\title{
Suplementação sobre o desempenho de bovinos de corte em pastagens: época do ano ${ }^{1}$
}

\author{
Supplementation on beef cattle \\ performance in pastures: season of the year ${ }^{1}$
}

\author{
Cleiton Luiz Tonello ${ }^{1 *}$; Antonio Ferriani Branco ${ }^{2}$; Claudio Yuji Tsutsumi; \\ Leonir Ribeiro Bueno ${ }^{4}$; Roman Castañeda Serrano ${ }^{4}$; Sabrina Marcantonio Conegli ${ }^{4}$
}

\begin{abstract}
Resumo
O presente estudo utilizou a meta-análise para avaliar os efeitos da suplementação sobre o desempenho de bovinos de corte em pastagens, no Brasil, classificando os dados pela época do ano. Foram revisados artigos publicados em revistas científicas indexadas no período compreendido entre os anos de 1999 e 2007. Foram utilizados 70 trabalhos e os dados dos artigos foram agrupados de acordo com a época do ano (Águas, Secas, Transição Águas/Secas e Transição Secas/Águas), e realizadas comparações entre o desempenho de animais não suplementados (controle) e os suplementados, para determinar o real efeito da suplementação sobre o desempenho animal e obter o ganho corrigido. A meta-análise foi realizada seguindo três análises seqüenciais: gráfica, de correlação e de variância. As equações de regressão foram obtidas através da covariância, e as correlações e nível de significância entre as variáveis dependentes e independentes foram obtidas com o PROC CORR do programa estatístico SAS. Na época das águas $(\mathrm{n}=49), 45,8 \%$ dos dados de ganho diário corrigido apresentaram-se entre 0,11 e $0,20 \mathrm{~kg} / \mathrm{dia}$, e na época das secas $(\mathrm{n}=54)$, observou-se que $21,2 \%$ dos dados de ganho diário corrigido encontram-se abaixo de $0,02 \mathrm{~kg} /$ dia e $21,2 \%$ dos dados acima de $0,40 \mathrm{~kg} /$ dia. $\mathrm{O}$ valor da correlação do ganho diário corrigido na época das secas com o consumo de proteína do suplemento é de $0,598(\mathrm{P}<0,01)$, e com a razão NDT/ PB da forragem o coeficiente de correlação é de $0,612(\mathrm{P}<0,01)$. Os dados avaliados mostram que a suplementação eleva o ganho diário corrigido de animais em pastagem.
\end{abstract}

Palavras-chave: Águas, secas, suplementos protéicos, suplementos energéticos, efeito substituição, meta-análise

\begin{abstract}
The present study used meta-analysis to assess the effects of supplementation on beef cattle performance in pastures in Brazil, classifying data by season of the year. There were reviewed articles published in journals indexed from 1999 to 2007. There were used 70 articles and data were grouped according to season of the year (Rainy, Drought, Transition Rainy/Drought and Transition Drought/Rainy). It was done comparisons between animals without supplement (control) and supplemented animals, to determine the real effect of supplementation on performance and to find the corrected daily gain in each
\end{abstract}

\footnotetext{
${ }^{1}$ Doutorando do Programa de Pós-Graduação em Zootecnia, Universidade Estadual de Maringá, UEM. E-mail: cleitontonello@ msn.com

${ }^{2}$ Prof. do Departamento de Zootecnia, Universidade Estadual de Maringá, Av. Colombo, 5790, 87020-900, Maringá, PR. E-mail: afbranco7757@gmail.com

${ }^{3}$ Prof. do Departamento de Zootecnia, Universidade Estadual do Oeste do Paraná, Rua Pernambuco, 1777, 85960-000, Marechal Cândido Rondon. E-mail: cytsutsu@unioeste.br

${ }^{4}$ Alunos do Programa de Pós-Graduação em Zootecnia, Universidade Estadual de Maringá, UEM Maringá, Paraná. E-mail: leonirbueno@hotmail.com; romancaser@hotmail.com; sa_zootecnia@hotmail.com

* Autor para correspondência
} 
study. A meta-analysis was performed using three sequential analyses: graphic, correlation and variance. The regression equations were obtained through the covariance, and the correlation and significance level, between dependent and independent variables were obtained using the SAS statistical program PROC CORR. In rainy season ( $\mathrm{n}=49) 45.8 \%$ of corrected daily gain ranged between 0.11 and $0.20 \mathrm{~kg} /$ day and for drought season $(\mathrm{n}=54)$ it was observed that $21.2 \%$ of the data were under $0.02 \mathrm{~kg} / \mathrm{d}$ and $21.2 \%$ above $0.40 \mathrm{~kg} /$ day. Correlation between corrected daily gain during drought and consumption of protein supplement was $0.598(\mathrm{P}<0.01)$, and with the TDN/PB ratio of forage this correlation was $0.612(\mathrm{P}<0.01)$. The evaluated data that supplementation increases the adjusted daily gain of animals on pasture.

Key words: Rainy season, drought season, protein supplement, energy supplement, substitution effect, meta-analysis

\section{Introdução}

Considerando o animal, a produtividade animal em pastagem é determinada pela carga animal e pelo ganho de peso individual dos animais. O ganho de peso dos animais é determinado por vários fatores dentre eles, o valor nutritivo da pastagem, e principalmente o consumo de forrageiras. $\mathrm{O}$ consumo de forragem por sua vez, depende de vários fatores, dentre os quais se encontram o valor nutritivo do pasto, a oferta de forragem e a estrutura do relvado (GOMIDE; GOMIDE, 2001; REIS et al., 2004).

O sistema convencional de produção animal é composto basicamente pelos estágios de ingestão do material forrageiro e de sua conversão em produto animal, sendo que cada um destes tem sua própria eficiência, cujo somatório determina a produção animal (EUCLIDES; EUCLIDES FILHO, 1997). Neste contexto, é de extrema importância a avaliação das inter-relações entre os bovinos e a forragem para iniciar um programa de suplementação em pastagens.

Pesquisas sobre produção e qualidade de forragens, geralmente baseiam-se em estudos de parcelas em canteiros, sem a presença animal. Pedreira, Mello e Otani (2001) relataram que as respostas de plantas forrageiras submetidas ao pastejo são, de maneira geral, diferentes daquelas submetidas ao corte mecânico. Os autores descreveram que a intensidade e freqüência de pastejo, espécie animal, método de apreensão da forragem, pisoteio, deposição de fezes e urina e, eventualmente, de saliva, podem causar alterações substanciais na persistência, produtividade e composição botânica do dossel.

Nas condições tecnológicas atuais, o uso de variáveis subjetivas para a definição de programas alimentares e nutricionais de bovinos de corte em pastagem não são suficientes. Por outro lado, as informações disponíveis sobre o ajuste nutricional através de variáveis objetivas são incipientes e pouco conclusivas, quando analisadas de forma isolada (ROSSI et al., 2008).

Como as pesquisas em ciência animal dependem de métodos estatísticos, as relações quantitativas podem ser mais bem exploradas através da meta-análise. Este método permite combinar os resultados de estudos realizados de forma independente (extraídos de trabalhos publicados) e sintetizar suas conclusões, ou mesmo obter uma nova conclusão (LUIZ, 2002). Este trabalho tem o objetivo de avaliar de forma sistêmica, utilizando a meta-análise, o efeito da suplementação sobre o desempenho de bovinos de corte em pastagens no Brasil com os dados classificados pela época do ano.

\section{Material e Métodos}

Foram revisados artigos publicados em revistas científicas indexadas pelo "Scielo" e utilizando ferramentas de busca na internet no período compreendido entre os anos de 1999 e 2007. Os artigos revisados avaliavam o efeito da suplementação concentrada para bovinos de corte em pastagens no Brasil. 
Após a seleção dos artigos, foi realizada uma triagem para evitar a classificação em duplicata de um mesmo estudo. Inicialmente, foram classificados e identificados 81 artigos que avaliaram o efeito da suplementação em bovinos de corte em pasto. Desses, foram selecionados 70 estudos que preenchiam as especificações para serem adicionados ao banco de dados do trabalho. Os artigos selecionados preencheram os seguintes requisitos mínimos: disponibilidade dos dados de consumo médio diário do suplemento; inclusão de tratamento controle (sem suplementação); disponibilidade dos dados de ganho de peso vivo dos animais; animais em regime de pastejo; disponibilidade dos dados das análises bromatológicas; ter sido conduzido em universidades ou estação de pesquisa, com protocolo experimental definido. Este último prérequisito foi inserido para assegurar que os animais tenham sido submetidos a um período de adaptação, anterior a coleta de dados. Os dados dos artigos foram agrupados de acordo com a época do ano de acordo com especificações de cada artigo.

As informações das secções de material e métodos e de resultados, de cada artigo, foram inseridas numa base de dados. Foram realizadas comparações entre animais não suplementados (controle) e animais suplementados para determinar o real efeito da suplementação sobre o desempenho.

A metodologia utilizada para definição das variáveis dependentes e independentes seguiu as orientações descritas por Moore et al. (1999). O ganho diário corrigido foi encontrado através da relação entre os tratamentos com suplemento e os tratamentos controle de cada artigo. Os efeitos da suplementação sobre o ganho diário ( $\mathrm{kg} / \mathrm{dia})$ foram quantificados de acordo com a seguinte fórmula:

$$
\text { Ganhoc }=\text { Ganhot }- \text { Ganhof }
$$

Sendo:

Ganhoc $=$ Ganho Diário Corrigido;

Ganhot $=$ Ganho de Peso Total;

Ganhof $=$ Ganho de Peso na Forragem (controle).
Um ganho diário corrigido positivo indicou que a suplementação produziu uma resposta adicional sobre o ganho diário em relação ao controle. Um ganho diário corrigido negativo indicou que a suplementação não produziu uma resposta adicional sobre o ganho diário. Foi encontrado um total de 135 comparações entre os tratamentos controle e os tratamentos suplementados.

Os dados dos artigos científicos foram agrupados de acordo com a época do ano (época das águas, época das secas, época transição águas/secas e transição secas/águas). Os valores agrupados foram convertidos em uma mesma base para comparação.

A concentração estimada de NDT total das dietas foi calculada segundo Moore et al. (1999):

NDTest $(\% M S)=[(C V F c s * N D T f)+(C M S s * N D T s)] /(C V F c s+C M S s)$

Sendo:

NDTest $=$ NDT estimado da dieta $(\% \mathrm{MS})$;

CVFcs = consumo voluntário de forragem com suplementação (\%PV, base MS);

NDTf $=$ NDT observado da forragem $(\% \mathrm{MS})$;

$\mathrm{CMSs}=$ consumo de matéria seca do suplemento (\%PV);

NDTs $=$ NDT observado do suplemento (\%MS).

Os efeitos da suplementação na concentração de NDT total da dieta foram quantificados através do desvio estimado do NDT total da dieta (NDTdes), calculado pela fórmula de Moore et al. (1999):

$$
\text { NDTdes }=\text { NDTobs }- \text { NDTest }
$$

Sendo:

NDTdes $=$ NDT do desvio;

NDTobs $=$ NDT efetivamente observado $(\% \mathrm{MS})$;

NDTest $=$ NDT estimado da dieta $(\% \mathrm{MS})$.

Um valor do desvio de NDT negativo indicou que o valor observado foi menor que o estimado, assim se o valor estimado for maior que o observado o valor do NDT da dieta é superestimado. Este valor 
não pode ser utilizado para indicar alterações na digestibilidade da forragem, do suplemento ou de ambos (MOORE et al., 1999).

A meta-análise foi realizada seguindo três análises seqüenciais: gráfica, de correlação e de variância. $\mathrm{Na}$ análise gráfica foi estudada a coerência biológica dos dados, propriedade em que o pesquisador pode avaliar, pelo seu conhecimento acumulado, se as informações sistêmicas da base de dados têm coerência com as respostas biológicas esperadas. $\mathrm{Na}$ análise de correlação, foram identificadas as variáveis correlacionadas na base. As equações de regressão foram obtidas através da covariância nos modelos de ANOVA (SAUVANT et al., 2005). As correlações e o nível de significância (1\%) entre as variáveis dependentes e independentes foram realizados usando o modelo PROC CORR do programa estatístico SAS (SAS, 2000). Muitas combinações de variáveis independentes foram realizadas para determinar as mais significativas para o trabalho. A seleção final das variáveis foi feita com base no valor obtido de $\mathrm{R}^{2}$, a partir de um conjunto de variáveis anteriormente testadas.
Nesse processo, as combinações de variáveis independentes testadas são selecionadas pelo investigador, em vez do computador.

Após a definição das variáveis a serem incluídas, estas foram analisadas através de regressão. As equações foram utilizadas para estimar o ganho diário corrigido, analisando cada comparação na avaliação adequada do subconjunto.

\section{Resultados e Discussão}

A distribuição percentual dos dados de acordo com a época do ano em relação ao ganho diário corrigido é apresentada na Tabela 1. Analisando os 135 dados retirados dos estudos analisados observou-se que 27,4\% dos animais tiveram o ganho diário corrigido entre 0,11 e $0,20 \mathrm{~kg} / \mathrm{dia}$. Foi observado que $85,19 \%$ dos ganhos diários corrigidos são positivos, com os dados variando de 0,02 a $0,40 \mathrm{~kg} / \mathrm{dia}$, o que mostra que o consumo de suplementos pelos bovinos em pastagens pode ter influência direta no aumento do ganho de peso.

Tabela 1. Percentagem da distribuição da época do ano de acordo com o ganho diário corrigido.

\begin{tabular}{|c|c|c|c|c|c|c|c|}
\hline Comparação & $<0,02$ & 0,02 a 0,05 & 0,06 a 0,10 & 0,11 a 0,20 & 0,21 a 0,30 & 0,31 a 0,40 & $>0,40$ \\
\hline \multicolumn{8}{|l|}{ Época } \\
\hline Águas, \% & 10,42 & 6,25 & 14,58 & 45,83 & 18,75 & 4,17 & - \\
\hline Secas, $\%$ & 21,15 & 7,69 & 3,85 & 17,31 & 17,31 & 11,54 & 21,15 \\
\hline Transição Águas/Secas, \% & - & - & - & 16,67 & 27,78 & 22,22 & 33,33 \\
\hline Transição Secas/Águas, \% & 20,00 & - & 6,67 & 20,00 & 13,33 & 33,33 & 6,67 \\
\hline
\end{tabular}

Na época das águas $(n=49) 45,8 \%$ dos dados de ganho diário corrigido ficaram entre 0,11 e 0,20 $\mathrm{kg} /$ dia. Durante a época das águas, as forrageiras tropicais possuem um adequado teor de proteína bruta, com alta degradabilidade no rúmen (POPPI; MCLENNAN, 1995), e a suplementação surtiu efeito positivo sobre o ganho médio corrigido em $89,58 \%$ dos dados.

A eficiência da suplementação na época das águas depende da oferta e da qualidade da forragem.
Apenas em 10,4 \% dos dados analisados foi registrado ganho diário corrigido negativo, e isso se deve possivelmente a elevada oferta de pastagem com bom valor nutritivo (MALAFAIA; CABRAL; VIEIRA, 2003).

Analisando a época das secas ( $\mathrm{n}=54)$ observouse que $21,15 \%$ dos dados de ganho diário corrigido encontram-se abaixo de $0,02 \mathrm{~kg} /$ dia e $21,15 \%$ dos dados acima de $0,40 \mathrm{~kg} /$ dia. Esta variabilidade pode ser devido a alteração do valor nutritivo das 
forragens tropicais e temperadas, muitas vezes não atingindo valores mínimos de $7 \%$ de proteína bruta, o que limita o desenvolvimento dos microrganismos do rúmen, a digestibilidade e o consumo da forragem, resultando em baixo desempenho dos animais (MINSON, 1990).

$\mathrm{Na}$ época de transição águas/secas 33,33 \% dos dados de ganho médio corrigido apresentaramse acima de $0,40 \mathrm{~kg} /$ dia e não foram observados valores negativos. Na época de transição secas/ águas $33,33 \%$ dos dados de ganho diário corrigido encontram-se entre 0,31 e $0,40 \mathrm{~kg} /$ dia e $20 \%$ dos dados mostraram perda de peso.

Os estudos avaliados tiveram em média 100 dias de período experimental, sendo que $77 \%$ destes foram realizados durante períodos fixos, com $36 \%$ nas águas e $41 \%$ nas secas. Apenas 22 $\%$ dos trabalhos foram realizados com o intuito de avaliar as épocas de transição, sendo $12 \%$ para a época de transição entre águas/secas e $10 \%$ para a época de transição entre secas/águas. Apenas $1 \%$ dos trabalhos foi de longa duração provavelmente devido ao tempo necessário para sua realização e custo do projeto.

Os coeficientes de correlação (R) e nível de significância $(\mathrm{P})$ entre a variável ganho diário corrigido com as variáveis analisadas estão apresentados na Tabela 2. Entre as variáveis que influenciaram o ganho diário corrigido encontramse o consumo de NDT do suplemento pela \% peso vivo (CNDTs \%PV), a \% de NDT do suplemento (\%NDTs), o consumo de proteína bruta do suplemento pela $\%$ do peso vivo (CPBs \%PV), a $\%$ proteína bruta do suplemento (\%PBs), a relação entre NDT/PB do suplemento (NDT/PBs), o consumo de matéria seca do suplemento pela $\%$ do peso vivo (CMSs \%PV), a \% de FDN da forragem (\%FDSf), a $\%$ de proteína bruta da forragem (\%PBf) e a relação entre NDT/PB da forragem.

Tabela 2. Coeficiente de correlação $(\mathrm{R})$ e nível de significância $(\mathrm{P})$ entre o ganho diário corrigido com as variáveis analisadas.

\begin{tabular}{llllllllll}
\hline & \multicolumn{7}{c}{ Variáveis } \\
\cline { 2 - 5 } & CNDTs & NDTs & CPBs & PBs & NDT/PBs & CMSs & FDNf & PBf & NDT/PBf \\
\hline Águas & & & & & & & & & \\
$\mathbf{R}$ & 0,130 & 0,555 & 0,057 & $-0,122$ & 0,410 & 0,177 & $-0,423$ & 0,143 & $-0,190$ \\
$\mathbf{P}$ & 0,6103 & 0,0060 & 0,7397 & 0,4185 & 0,0519 & 0,2947 & 0,0249 & 0,4287 & 0,3145 \\
\hline Secas & & & & & & & & & \\
$\mathbf{R}$ & 0,050 & 0,087 & 0,598 & $-0,080$ & $-0,090$ & 0,271 & 0,341 & $-0,258$ & 0,612 \\
$\mathbf{P}$ & 0,8222 & 0,6646 & $<0,0001$ & 0,6181 & 0,6683 & 0,0625 & 0,0451 & 0,0915 & 0,0002 \\
\hline
\end{tabular}

Segundo Zervoudakis, Paulino e Detmann (1999) na época das águas, os animais suplementados com fontes protéicas de menor degradabilidade ruminal podem ganhar ao redor de $0,9 \mathrm{~kg} / \mathrm{dia}$. Observou-se que o ganho diário corrigido está correlacionado com a concentração de NDT do suplemento $(\mathrm{R}=0,555$; $\mathrm{P}<0,01$ ), o que demonstra que o fornecimento de mais NDT poderia melhorar a razão NDT/ PB da dieta e aumentar a utilização da proteína do pasto, permitindo um melhor crescimento dos microrganismos ruminais.
$\mathrm{Na}$ época das secas as forrageiras tropicais normalmente apresentam um menor valor nutritivo, com quantidades de nutrientes suficientes apenas para manutenção ou pequenos ganhos, e nesta situação suplementos protéicos de baixo custo, que maximizem o consumo de forragem disponível, são os mais recomendáveis (REIS; RODRIGUES; PEREIRA, 1997). Na época das secas o ganho diário corrigido foi correlacionado com o consumo de proteína do suplemento ( $\mathrm{R}=0,598 ; \mathrm{P}<0,01)$, e com 
a razão NDT/PB da forragem $(\mathrm{R}=0,612 ; \mathrm{P}<0,01)$, e desta forma, o fornecimento de suplementos protéicos nesta época do ano tende a elevar o consumo de alimentos e elevar o desempenho animal.

Os efeitos associativos entre a suplementação de animais e as forrageiras disponíveis são demonstrados em termos de ganho diário corrigido. Dos estudos analisados poucos foram os casos, em que não ocorreu ganho de peso. $\mathrm{O}$ efeito do suplemento sobre o ganho de peso foi quantificado através do ganho diário corrigido.

$\mathrm{Na}$ época das águas o consumo de NDT do suplemento foi de $0,417 \%$ do $\mathrm{PV} /$ dia, resultando em um ganho diário corrigido de $0,152 \mathrm{~kg} / \mathrm{dia}$, e variação 0,060 e $0,310 \mathrm{~kg} / \mathrm{dia}$. Na época das secas $(n=23)$, onde a incidência de chuvas é menor e os dias tornam-se mais curtos reduzindo a produção de forragens tropicais, os animais tiveram uma média de ganho diário corrigido de $0,244 \mathrm{~kg} / \mathrm{dia}$, com 83,96\% dos dados analisados apresentando ganhos positivos. Foi observado um consumo de NDT do suplemento pelos animais de 0,631\% do $\mathrm{PV} / \mathrm{dia}$, valor superior ao consumido na época das águas, isso provavelmente devido ao menor valor nutritivo das forragens na época das secas, o que leva os animais a consumir mais nutrientes para suprir as deficiências das forragens. $\mathrm{O}$ maior ganho diário corrigido na época das secas deve-se provavelmente a maior quantidade de suplemento oferecida aos animais devido a baixa qualidade da forragem. Como o ganho diário corrigido tem como base o efeito da suplementação sem o efeito da forragem fica evidente que na época das secas a suplementação tem maior efeito no ganho diário corrigido que na época das águas.

As forrageiras tropicais, em geral, apresentam limitações nutricionais em relação às forrageiras temperadas, que se agravam à medida que amadurecem, principalmente na época das secas
(ANDRADE, 1995). Na época das secas, em muitas situações, o animal pode perder peso (POPI; McLENNAN, 1995; EUCLIDES FILHO; EUCLIDES, FIGUEIREDO, 1997) e apresentar o que é denominado de "efeito sanfona", ou seja, ocorrem altos ganhos de peso na época das águas e pouco ganho de peso na época das secas, ampliando com isso, a idade de abate (CARDOSO; VITTO; NOGUEIRA, 1998).

$\mathrm{Na}$ época de transição águas/secas o consumo médio de NDT do suplemento foi de $0,484 \%$ do $\mathrm{PV} /$ dia e tiveram um ganho diário corrigido de $0,463 \mathrm{~kg} /$ dia. Na época de transição secas/águas os animais apresentaram um consumo de NDT do suplemento de $0,590 \%$ do $\mathrm{PV} /$ dia, tendo um ganho diário corrigido de $0,322 \mathrm{~kg} / \mathrm{dia}$.

O efeito da concentração de nutrientes digestíveis totais (NDT) do suplemento, em relação ao ganho diário corrigido, $\mathrm{kg} /$ dia, classificado de acordo com a época do ano é mostrado na Figura 1. Os suplementos utilizados na época das águas $(n=23)$ apresentaram uma concentração média de NDT de $72,02 \%$, com variação entre $53,10 \%$ e $86,70 \%$, e o ganho diário corrigido foi de $0,134 \mathrm{~kg} / \mathrm{dia}$, com valor mínimo de $-0,078 \mathrm{~kg} /$ dia e máximo de 0,310 $\mathrm{kg} /$ dia.

$\mathrm{Na}$ época das secas $(\mathrm{n}=27)$ tiveram uma concentração de NDT de 73,34 \% e o ganho diário corrigido dos animais foi de $0,328 \mathrm{~kg} / \mathrm{dia}$, variando entre $-0,243 \mathrm{~kg} / \mathrm{dia}$ e $0,830 \mathrm{~kg} / \mathrm{dia}$. O valor do ganho diário corrigido na época das secas é superior que o da época das águas, possivelmente devido ao maior efeito aditivo do suplemento nas secas. As variações entre as estações do ano afetam negativamente a produtividade animal, e assim, para manter uma relação adequada entre a produção individual e o rendimento por unidade de área, deve-se utilizar a estratégia da suplementação com o objetivo de maximizar o consumo e digestibilidade da forragem disponível(REIS; RODRIGUES; PEREIRA, 1999). 


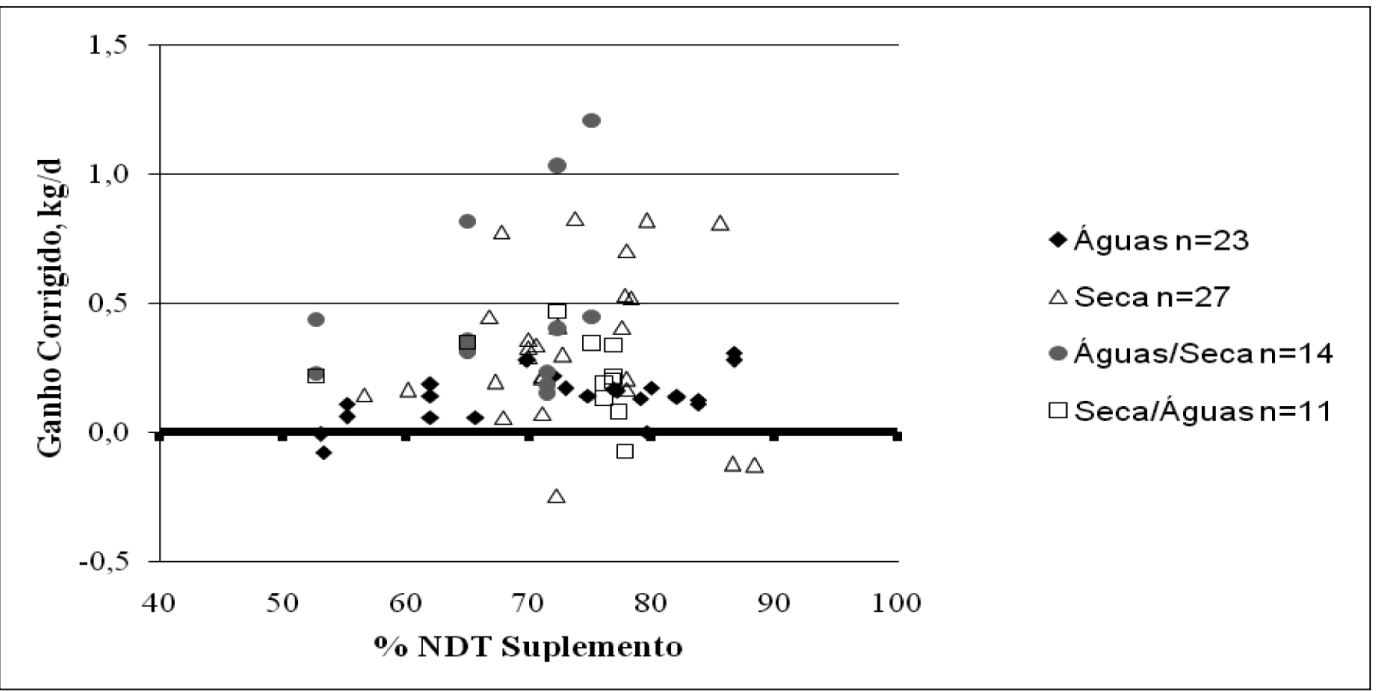

Figura 1. Efeito da percentagem de nutrientes digestíveis totais (NDT) do suplemento, em relação ao ganho diário corrigido, kg/dia, classificado de acordo com a época do ano.

O efeito dos teores de proteína bruta $(\mathrm{PB})$ do suplemento, em relação ao ganho diário corrigido, $\mathrm{kg} /$ dia, classificado de acordo com a época do ano é mostrado na Figura 2. Na época das águas $(n=46)$ os suplementos utilizados apresentam concentração média de proteína bruta de 25,21\% variando entre $6,59 \%$ e $48 \%$. Nesta época os animais apresentaram um ganho diário corrigido de $0,137 \mathrm{~kg} / \mathrm{dia}$, com valores mínimos e máximos de $-0,078$ e $0,335 \mathrm{~kg} /$ dia, respectivamente. Na época das secas ocorre um decréscimo da qualidade das forrageiras tropicais e com isso devem ser fornecidos suplementos com maior concentração de nutrientes, principalmente proteína. O teor médio de proteína bruta dos suplementos na época das secas foi $31,87 \%$, variando de 10,10 a $52,50 \%$.

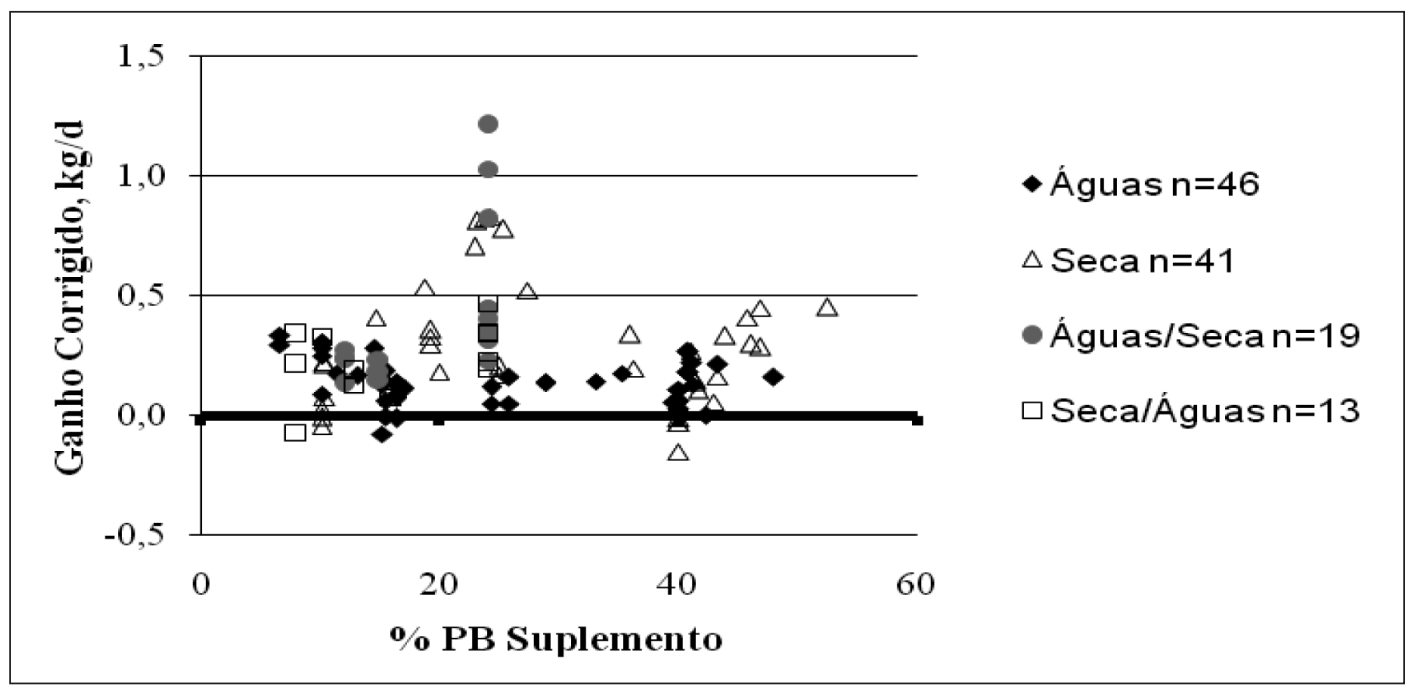

Figura 2. Efeito da percentagem de proteína bruta (PB) do suplemento, em relação ao ganho diário corrigido, $\mathrm{kg} / \mathrm{dia}$, classificado de acordo com a época do ano. 
Segundo Pascoal, Restle e Roso (1999), o uso da suplementação energética em pastagens na época das águas proporciona melhor aproveitamento de grande quantidade de proteína produzida pelas forrageiras utilizadas, propiciando maior ganho de peso diário por animal.

$\mathrm{Na}$ época das águas $(\mathrm{n}=23)$ a relação média NDT/PB do suplemento foi de 4,36 e na época das secas $(n=24)$ foi de 3,26. Ambas as relações dos suplementos apresentam-se abaixo de 7 , valor que garante boa fermentação ruminal. Na época das secas, porém, a relação foi menor, o que é coerente quando analisamos a razão NDT/PB da forragem, que necessita da correção do teor de proteína. $\mathrm{O}$ ganho diário corrigido dos animais na época das águas foi de $0,134 \mathrm{~kg} /$ dia e nas secas foi de 0,389 $\mathrm{kg} /$ dia. O maior ganho médio corrigido nas secas mostra que a correção desta relação entre NDT e PB é mais importante nesta época do ano.

Os dados analisados na época das águas $(n=37)$ mostraram que os animais tiveram um consumo de suplemento de $0,550 \%$ do PV/dia, e ganho diário corrigido de $0,144 \mathrm{~kg} /$ dia. Nesta época em que as forrageiras tropicais estão na plenitude de qualidade e quantidade disponível para os animais, observouse que $10,8 \%$ dos dados apresentaram valores negativos de ganho diário corrigido. $\mathrm{O}$ desempenho e o consumo dos animais durante a época das secas $(\mathrm{n}=48)$ foram semelhantes ao da época das águas, com os animais tendo um ganho diário corrigido de $0,178 \mathrm{~kg} /$ dia e um consumo de suplemento de $0,58 \%$ do PV/dia, porém, 20,83\% dos dados apresentaram um ganho diário corrigido negativo nesta época.

Observou-se que na época das águas o teor de proteína bruta é maior que nas secas. $\mathrm{Na}$ época das águas $(n=33)$ a concentração de proteína bruta das forragens foi de 10,6\% enquanto na época das secas houve uma redução de $25,7 \%$ do teor de proteína bruta das forragens, atingindo valor médio de 7,88
\%. Esta alteração na qualidade da forragem, no entanto, deve ser compensada com o acréscimo de proteína na suplementação, com isso o ganho diário corrigido dos animais na época das águas foi de $0,142 \mathrm{~kg} /$ dia e na época das secas foi de 0,255 $\mathrm{kg} /$ dia. Este fato também foi verificado nas épocas de transição, sendo que na época de transição águas/secas o valor de proteína bruta médio foi de 6,48 \% e na transição secas/águas foi de 11,3\%, isso demonstrou que o efeito da época do ano é intenso em relação a qualidade da forragem e tem interferência no ganho de peso animal.

Quando o suplemento é fornecido, a redução no consumo de forragem pode ser tanto desejável como indesejável. Em condições de suplementação, novas variáveis interferem no consumo de nutrientes, estando associadas às relações de substituição de forragem por suplemento e/ou adição no consumo total de matéria seca, dependendo das características da base forrageira e do suplemento (HODGSON, 1990). Isto pode ser verificado, comparando-se a época das águas com o das secas. Na época das águas a produção e a qualidade das forrageiras tropicais são excelentes, porém nas secas, ocorre a redução da qualidade com a maturidade das forragens, e desta forma, a suplementação é uma alternativa para elevar o ganho de peso animal, podendo ocorrer efeito de substituição da forragem pelo suplemento.

O efeito da suplementação sobre o consumo de NDT em \% do peso vivo do animal e pelo desvio de NDT total com base na matéria seca, classificado de acordo com a época do ano, é apresentada na Figura 3. Os efeitos da suplementação na concentração de NDT total da dieta são quantificados através do desvio esperado do NDT total da dieta (\%MS). $\mathrm{Na}$ época da seca foi observado um valor médio de desvio de NDT de 2,208, indicando que o valor do NDT observado nas dietas foi superior ao NDT estimado, demonstrando que o valor do NDT estimado tem sido subestimado. 


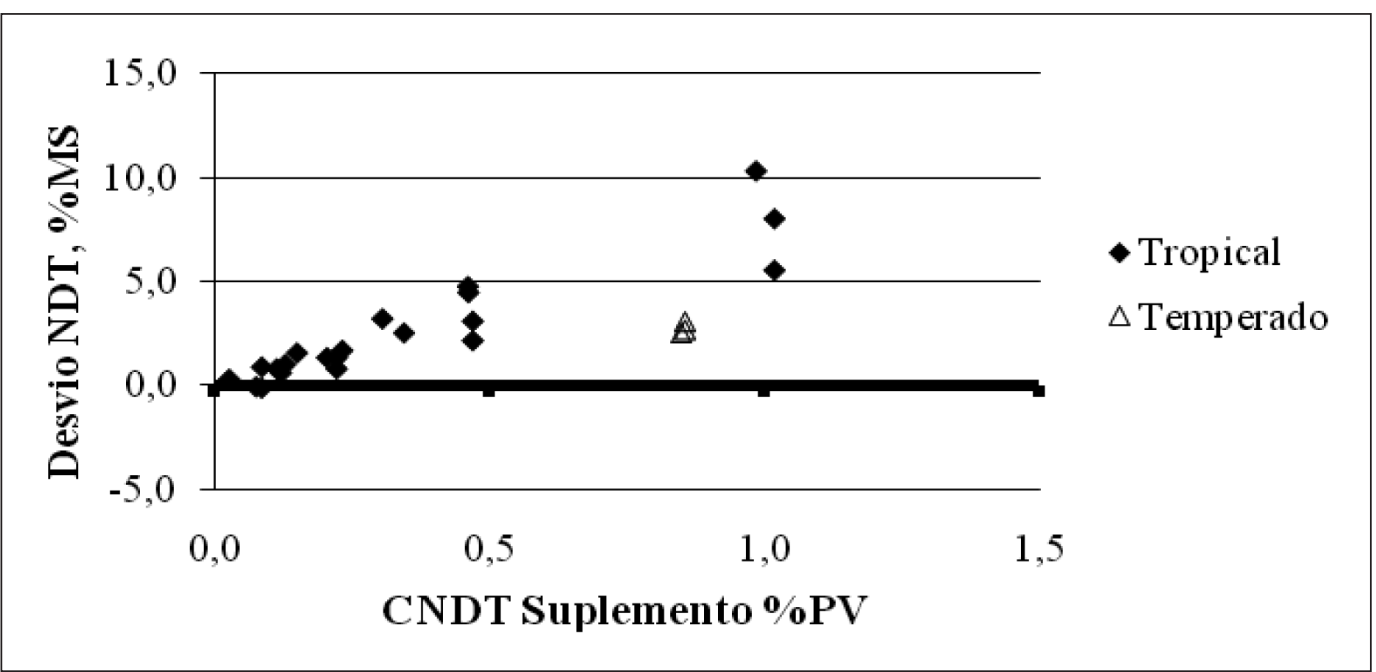

Figura 3. Efeito do consumo de NDT do suplemento em \% do peso vivo do animal pelo desvio de NDT total com base na matéria seca, classificado de acordo com a época do ano.

Para a época de transição entre águas/secas o valor do NDT estimado foi subestimado, pois a média do desvio de NDT foi de 2,454. O maior desvio de NDT foi encontrado para a época de transição entre secas/ águas com valor médio de 4,028. Em todos os casos verificou-se que, conforme o consumo de NDT do suplemento aumenta o desvio é aumentado, fazendo com que o valor do NDT estimado seja subestimado com maior intensidade conforme o consumo de NDT aumenta.
As equações apresentadas na (Tabela 3) permitiram a estimativa do ganho diário corrigido, sendo as co-variáveis a razão NDT/PB da forragem (NDT/PBf), o consumo de proteína bruta do suplemento em \%PV (CPBs), a porcentagem de proteína bruta do suplemento (PBs), a porcentagem de proteína bruta da forragem (PBf), o consumo de nutrientes digestíveis totais do suplemento em $\% \mathrm{PV}$ (CNDTs), o consumo de matéria seca do suplemento em \%PV (CMSs).

Tabela 3. Equações para estimar o ganho diário corrigido (GMD) obtido por análise de covariância utilizando covariáveis dos suplementos e forrageiras.

\begin{tabular}{lllllc}
\hline \multicolumn{1}{c}{ Respostas (GMD) } & \multicolumn{1}{c}{ Covariáveis (x) } & N & dp & $\mathbf{R}^{\mathbf{2} \%}$ & Equação \\
\hline Águas & FDNf (\%PV) & 28 & 0,090 & 21,56 & $\mathrm{y}=0,0004 \mathrm{x}^{2}-0,0631 \mathrm{x}+2,6248$ \\
Águas & PBs (\%PV) & 46 & 0,090 & 22,93 & $\mathrm{y}=0,0004 \mathrm{x}^{2}-0,0231 \mathrm{x}+0,3891$ \\
Águas & NDTs (\%PV) & 23 & 0,090 & 33,73 & $\mathrm{y}=-0,0002 \mathrm{x}^{2}+0,0271 \mathrm{x}-0,9622$ \\
\hline Seca & PBf (\%PV) & 45 & 0,255 & 23,92 & $\mathrm{y}=0,0039 \mathrm{x}^{2}-0,1068 \mathrm{x}+0,685$ \\
Seca & NDT/PBs & 24 & 0,245 & 32,25 & $\mathrm{y}=-0,0443 \mathrm{x}^{2}+0,3487 \mathrm{x}-0,1516$ \\
Seca & NDT/PBf & 32 & 0,255 & 65,08 & $\mathrm{y}=0,004 \mathrm{x}^{2}-0,0611 \mathrm{x}+0,3371$ \\
\hline Águas/Seca & PBs (\%PV) & 19 & 0,303 & 30,13 & $\mathrm{y}=0,0041 \mathrm{x}^{2}-0,1226 \mathrm{x}+1,0965$ \\
Águas/Seca & PBf (\%PV) & 15 & 0,324 & 34,77 & $\mathrm{y}=0,2959 \mathrm{x}^{2}-3,4726 \mathrm{x}+10,354$ \\
Águas/Seca & NDT/PBs & 14 & 0,324 & 38,50 & $\mathrm{y}=-0,2979 \mathrm{x}^{2}+2,0683 \mathrm{x}-2,8706$ \\
\hline Seca/Águas & PBf (\%PV) & 13 & 0,149 & 31,93 & $\mathrm{y}=0,0048 \mathrm{x}^{2}-0,1109 \mathrm{x}+0,7865$ \\
\hline
\end{tabular}




\section{Conclusões}

Os dados avaliados mostram que a suplementação eleva o ganho diário corrigido de animais em pastagem, principalmente na época das secas.

\section{Referências}

ANDRADE, P. Alimentação de bovinos em épocas criticas. In: PEIXOTO, A. M.; MOURA, J. C.; FARIA, P. F. (Ed.). Nutrição de bovinos. Conceitos básicos e aplicados. 2. ed. Piracicaba: Fundação de Estudos Agrários Luiz de Queiroz, 1995. p. 239-250.

CARDOSO, A. G.; VITTO, G.; NOGUEIRA, M. P. A importância da suplementação protéica para os animais. Revista Pecuária de Corte, São Paulo, v. 8, n. 80, p. 7074, 1998.

EUCLIDES FILHO, K.; EUCLIDES, V. P. B.; FIGUEIREDO, G. R. Efeito da suplementação com concentrado sobre a idade de abate e características de carcaça do animal Nelore. Revista Brasileira de Zootecnia, Viçosa, MG, v. 26, n. 6, p. 1096-1102, 1997.

EUCLIDES, V. P. B.; EUCLIDES FILHO, K. Avaliação de forrageiras sob pastejo. In: JOBIM, C.C.; SANTOS, G. T.; CECATO, U. (Ed.). Simpósio sobre avaliação de pastagens com animais. Maringá: Cooper Graf. Artes Gráficas Ltda., 1997. p. 85-111.

GOMIDE, J. A.; GOMIDE, C. A. M. Utilização e manejo de pastagens. In: REUNIÃO ANUAL DA SOCIEDADE BRASILEIRA DE ZOOTECNIA, 38., 2001, Piracicaba. Anais... Piracicaba: Sociedade Brasileira de Zootecnia, 2001. CD-ROM. (Forragicultura. Semi, 54).

HODGSON, J. Grazing management. Science into praactice. Essex: Longman England, 1990. 203 p.

LUIZ, A. J. B. Meta-análise: definição, aplicações e sinergia com dados espaciais. Cadernos de Ciência e Tecnologia, Embrapa, v. 19, n. 3, p. 407-428, 2002.

MALAFAIA, P.; CABRAL, L. S.; VIEIRA, R. A. M.; COSTA, R. M.; CARVALHO, C. A. B. Suplementação protéico-energética para bovinos criados em pastagens: Aspectos teóricos e principais resultados publicados no Brasil. Livestock Research for Rural Development, v.1 5, n. 12, 2003. Disponível em: <http:/www.cipav.org. co/lrrd//rrd15/12/mala1512.htm >. Acesso em: 28 mar. 2007.

MINSON, D. J. Forage in ruminant nutrition. San Diego: Academic Press, Inc., 1990.

MOORE, J. E.; BRANT, M. H.; KUNKLE, W. E.; HOPKINS, D. I. Effects of supplementation on voluntary forage intake, diet digestibility, and animal performance. Journal of Animal Science, Madison, v. 77, p. 122-135, 1999.

PASCOAL, L. L.; RESTLE, J.; ROSO, C. Desempenho e economicidade da suplementação em pastagem. In: RESTLE, J. (Ed.). Confinamento, pastagens $e$ suplementação para produção de bovinos de corte. Santa Maria: UFSM, 1999. p. 62-84.

PEDREIRA, C. G. S.; MELLO, A. C. L.; OTANI, L. $O$ processo de produção de forragem em pastagens. In: MATTOS, W. R. S. (Ed.). A produção animal a pasto na visão dos brasileiros. Sociedade Brasileira de Zootecnia. Piracicaba: FEALQ, 2001. 927 p.

POPPI, D. P.; McLENNAN, S. R. Protein and energy utilization by ruminants at pasture. Journal of Animal Science, Madison, v. 73, n. 1, p. 278-290, 1995.

REIS, R. A.; RODRIGUES, L. R. A.; PEREIRA, J. R. A. Suplementação como estratégia de manejo de pastagem. In: SIMPÓSIO SOBRE MANEJO DE PASTAGEM, 13., 1997, Piracicaba. Anais... Piracicaba: FEALQ, 1997. p. 123-150.

REIS, R. A.; RODRIGUES, L. R.; PEREIRA, J. R. A suplementação como estratégia de manejo da pastagem. In: PEIXOTO, A. (Ed.). Produção de bovinos a pasto. Piracicaba: Fundação de Estudos Agrários "Luiz de Queiroz" 1999. p. 123-150.

REIS, R. S.; BERTIPAGLIA, L. M. A.; FREITAS, D.; MELO, G. M. P.; BALSAlOBRE, M. A. A. Suplementação protéico-energética e mineral em sistemas de produção de gado de corte nas águas e nas secas. In: SIMPOSIO SOBRE BOVINOCULTURA DE CORTE: PECUÁRIA DE CORTE INTENSIVA NOS TROPICOS, 5., 2004, Piracicaba. Anais... Piracicaba: FEALQ, 2004. p. 171-226.

ROSSI, C.A. R.; LOVATTO, P.A.; WESCHENFELDER, V. A.; LEHNEN, C. R.; FRAGA, B. N. Metanálise da relação entre espessura de toicinho e variáveis corporais e reprodutivas de porcas gestantes e lactantes. Ciência Rural, Santa Maria, v. 38, n. 1, p. 206-212, jan./fev. 2008.

SAS Institute Inc. Statistical Analysis System user's guide. Version 8. 2. ed. Cary: SAS Institute, USA, 2000.

SAUVANT, D.; SCHMIDELY, P. O.; DAUDIN, J. J. Les méta-analyses des données expérimentales: aplications em nutrition animale. Productions Animales, INRA, v. 18, n. 1, p. 23-33, 2005.

ZERVOUDAKIS, J. T.; PAULINO, M. F.; DETMANN, E. Suplementação de bovinos mestiços na época das águas.Ganho de peso e rendimento de carcaça. In: REUNIÃO ANUAL DA SOCIEDADE BRASILEIRA DE ZOOTECNIA, 36., 1999, Porto Alegre. Anais... SBZ/ Gnoisis. 1999. CD-ROM. 